\title{
Vowel Length Distinctions In Plains Cree
}

\author{
Angeliki Athanasopoulou ${ }^{* 1}$ and Darin Flynn ${ }^{\dagger 1}$ \\ ${ }^{1}$ School of Languages, Linguistics, Literatures and Cultures, University of Calgary, Calgary, Alberta
}

\section{Introduction}

Cree is a dialect continuum spoken across much of Canada, from British Columbia to Labrador. Cree inherited from Proto-Algonquian a phonological contrast between "long" and "short" vowels which is equivocal in nature [1]. Long/short pairs are notoriously distinct in the vowel spaces of Eastern dialects [2]. In Northern East Cree, for instance, "this distinction is realized as a contrast in vowel quality: historically long vowels have become tense and historically short vowels are lax" [3].

For Western dialects, too, Muehlbauer [4] warns that "we should not treat the purely durational analysis ... as a foregone conclusion." He conducted a pilot acoustic study of Plains Cree vowels (/a:, a, o: o, i:, i, e:/) based on mid20th-century recordings of three women from Alberta and Saskatchewan. While there is "strong use of duration to contrast long and short pairs of phonemes, ... all vowel pairs also differ in terms of their quality - either F1, F2, or both" [4].

Harrigan \& Tucker [5] ran a similar pilot study of Plains Cree vowels with three women from Maskwacis, Alberta, with similar results, except that the pair $/ 0: /-/ \mathrm{o} /$ showed no reliable differences in quality —only quantity.

This paper reports on a third pilot study, based on publically available recordings of two noted teachers of Plains Cree: Mrs. Dolores Sand from Muskeg Lake Cree Nation in central Saskatchewan, and Dr. Jean Okimasis from White Bear First Nation in southern Saskatchewan. Both were raised with Plains Cree as a first language. Mrs. Sand was recorded when she was 58 years old [6], and Dr. Okimasis when she was 60 [7].

\section{Method}

We used Praat [7] to annotate and measure vowels and adjacent consonants extracted from the first ten minutes of narration by Mrs. Sand [4], and a corresponding number of tokens from Dr. Okimasis uttering words and phrases (workbook sessions 10, 11, 13) [5]. We did not restrict ourselves to vowels flanked by particular consonants (cf. /t, $\mathrm{k} /$ in [4]; /t, s/ in [5]), but we avoided word-final vowels as well as vowels intertwined with $/ \mathrm{h}, \mathrm{j}$, w/. We also avoided instances of syncope, which can result in compensatorily lengthened consonants (cf. [3]). We used a Praat script that reported mean formant values only in the middle $60 \%$ portion of vowels, to reduce effects from consonant transitions and anticipatory vocalic assimilation. The latter co-articulatory effect is rather forceful Plains Cree, as

angeliki.athanasopou @ucalgary.ca

† dflynn@ucalgary.ca illustrated in Fig. 1.

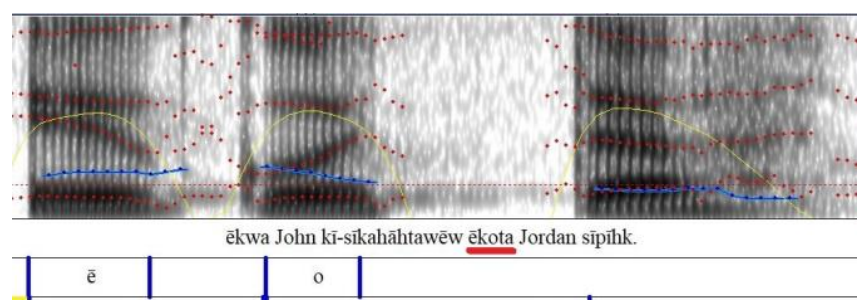

Figure 1: Anticipatory vocalic assimilation in Plains Cree ēkota

\section{Results}

\subsection{Vowel quality}

As shown in Fig. 2, Mrs. Sand clearly differentiates all vowels in terms of quality, except that the standard deviation of $/ 0 /$ encompasses that of $/ 0: /$. This confirms what Muehlbauer found: "while the hypothesized short/long vowel pairs do indeed have a strong durational contrast, the majority of vowel pairs are also distinguished by their formants. In all cases, the long vowel occupies a more extreme position in the vowel space. Plains Cree thus appears to show both a quantity and a quality contrast in its vowel pairs" [4].

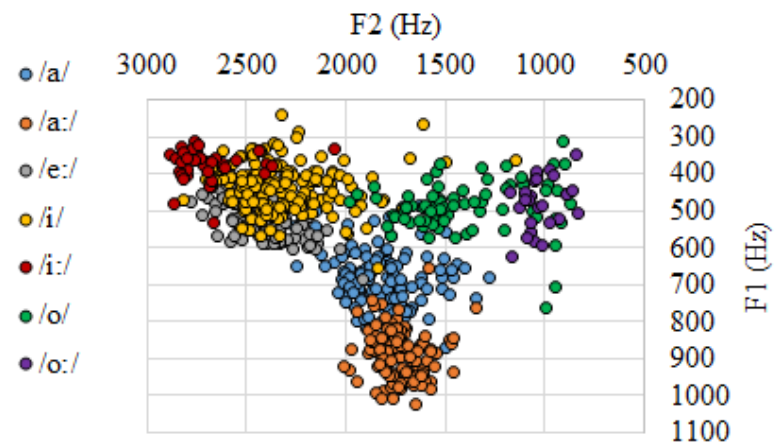

Figure 2: Vowel qualities (non-final position) - Dolores Sand

As shown in Fig. 3 on the next page, Dr. Okimasis also differentiates short/long pairs in terms of quality, but her vowel space shows far more overlap than Mrs. Sand'sparticularly in the vowel pairs /o, o:/ and /a, a:/, as well as between them. This is similar to what Harrigan \& Tucker [5] reported for Maskwacis, Alberta.

\subsection{Vowel duration}

Mrs. Sand and Dr. Okimasis both strongly differentiate all long/short vowel pairs in terms of duration, as shown in Figs. 4 and 5 on the next page. To give an idea, Mrs. Sand's 
/a:/ is generally 2.6 times longer than her /a/ $(156 \mathrm{~ms}$ $(\mathrm{N}=114)$ vs. $59 \mathrm{~ms}(\mathrm{~N}=127))$. Similarly, her / $\mathrm{i} / \mathrm{is} 2.7$ times longer than her /i/; and her /o:/ is 2.1 times longer than her /o/.

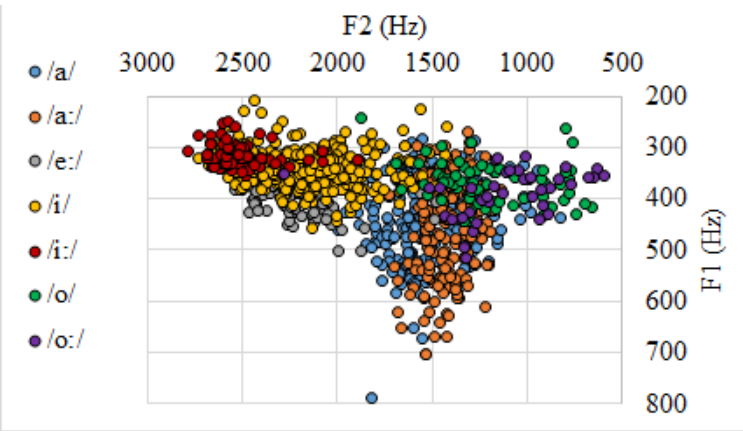

Figure 3: Vowel qualities - Jean Okimasis

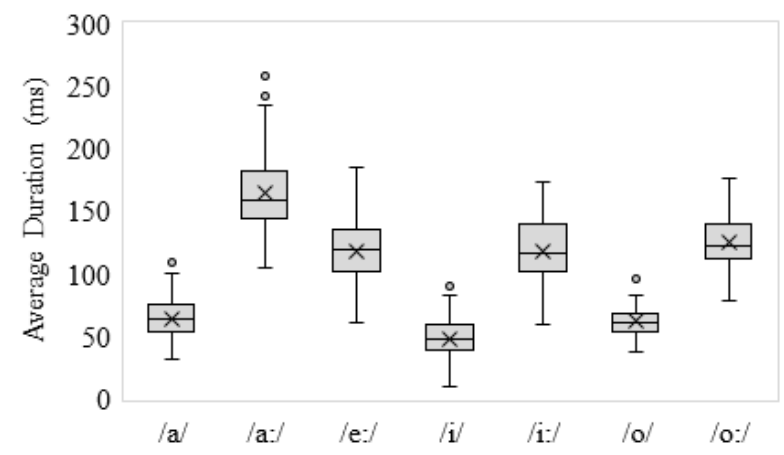

Figure 4: Vowel duration (non-final position) - Dolores Sand

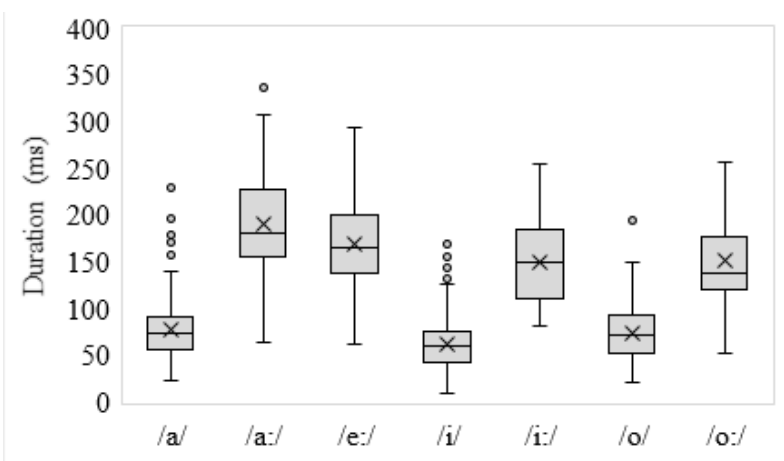

Figure 5: Vowel duration - Jean Okimasis

\subsection{Contrast reduction}

The striking durational difference between short and long vowels appears to be greatly reduced in closed syllables. In practice, only $/ \mathrm{s} /$ and $/ \mathrm{h} /$ may close a non-final syllables in Plains Cree. Table 1 illustrates this contrast reduction in Mrs. Sand's speech (with admittedly low Ns).

In practice, however, the durational difference between short and long vowels remains significant in closed syllables. On the other hand, coda consonants are a bit longer after short vowels, and/or they are a bit shorter after long vowels. The overall effect is a contrast reduction in the rhyme.
Table 1: Contrast reduction with VC. - Dolores Sand

\begin{tabular}{|cc|}
\hline /as./ & /a:s./ \\
\hline 245 & 273 \\
$(\mathrm{~N}=8)$ & $(\mathrm{N}=4)$ \\
\hline /is./ & /i:s./ \\
\hline 213 & 241 \\
$(\mathrm{~N}=15)$ & $(\mathrm{N}=3)$ \\
\hline
\end{tabular}

\begin{tabular}{|cc|}
\hline /ah.C/ & /a:h.C/ \\
\hline 296 & 319 \\
$(\mathrm{~N}=13)$ & $(\mathrm{N}=11)$ \\
\hline /ih.C/ & /i:h.C/ \\
\hline 255 & 270 \\
$(\mathrm{~N}=12)$ & $(\mathrm{N}=12)$ \\
\hline
\end{tabular}

Fig. 6 below illustrates this effect in Dr. Okimasis's speech. Durational differences are reduced but remain significant in short/long vowel pairs before syllable-final /s/ or $/ \mathrm{h} /$ (as simple t-tests reveal). However, durational differences between rhymes with short vs. long vowels are not always significant, particularly in syllables closed by $/ \mathrm{h} /$. This contrast reduction at the level of the rhyme is likely the basis for this remark from Wolfart [9]: "In the dialects of central Saskatchewan ..., vowel length tends to be indeterminate before preaspirated stops."
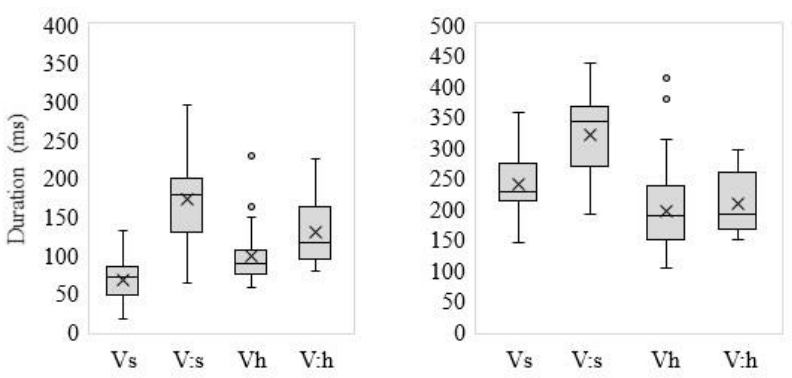

Figure 6: Nucleus vs. Rhyme duration - Jean Okimasis

\section{References}

[1] MacKenzie, M. 1980. Towards a dialectology of CreeMontagnais-Naskapi. Doctoral dissertation, University of Toronto.

[2] Dyck, C., Junker, M.-O., \& Logan, K. 2010. Phonetic and phonological evidence for a vowel merger in Southern East Cree. UBC Working Papers in Linguistics 29, 98-114. [2] Muehlbauer, J. 2012. Vowel spaces in Plains Cree. Journal of the International Phonetic Association, 42(3), 91-105.

[3] Knee, S. 2014. Vowel devocalization in Northern East Cree. Canadian Journal of Linguistics, 59, 303-338.

[4] Muehlbauer, J. 2012. Vowel spaces in Plains Cree. Journal of the International Phonetic Association, 42(1), 91-105.

[5] Harrigan, A. \& Tucker, B. 2015. Vowels spaces and reduction in Plains Cree. Canadian Acoustics, 43(3), 1-2.

[6] Canadian Bible Society. 2010. miywācimowin $k \bar{a}-k \bar{l}-$ masinahahk Mark. North York, ON: Canadian Bible Society.

[7] Okimasis, J. 1999. Cree, language of the Plains workbook. Regina, SK: University of Regina Press.

[8] Boersma, P. \& Weenink, D. 2018. Praat: doing phonetics by computer [Computer program]. Version 6.0.43, retrieved 8 September 2018 from http://www.praat.org/

[9] Wolfart, H. C. 1996. Sketch of Cree, an Algonquian language. In Goddard, I. (ed.), Handbook of American Indians, Vol. 17: Languages, 390-439. Washington, DC: Smithsonian Institute. 